\title{
Potential roles of masculine role discrepancy, discrepancy stress, and self-esteem in affecting addictive use of social networking sites among Chinese men: A random population-based study
}

\author{
XUE YANG ${ }^{1,2}$, JOSEPH T. F. LAU ${ }^{1,2 *}$, ZIXIN WANG ${ }^{1,2}$ and MASON C. M. LAU ${ }^{1}$ \\ ${ }^{1}$ Faculty of Medicine, Centre for Health Behaviours Research, JC School of Public Health and Primary Care, \\ The Chinese University of Hong Kong, Hong Kong SAR, China \\ ${ }^{2}$ JC School of Public Health and Primary Care, The Chinese University of Hong Kong Shenzhen Research Institute, Shenzhen, China
}

(Received: January 15, 2018; revised manuscript received: April 16, 2018; second revised manuscript received: April 23, 2018; third revised manuscript received: July 27, 2018; fourth revised manuscript received: August 2, 2018; accepted: August 9, 2018)

\begin{abstract}
Background and aims: Masculine role discrepancy (i.e., men perceiving themselves not living up to the ideal manhood and being less masculine than the typical "man") and related discrepancy stress were associated with some risk behaviors. No study has looked at their relationships with addictive use of social networking sites (SNSs), an emerging potential public health concern. The study constructed a moderated mediation model to test whether masculine role discrepancy would be positively associated with discrepancy stress, which would, in turn, be positively associated with addictive use of SNS, and whether self-esteem would buffer (moderate) the association between masculine role discrepancy and discrepancy stress. Methods: A random population-based cross-sectional telephone survey interviewed 2,000 Hong Kong male adults in the general population. Results: Currently unmarried and non-cohabiting, younger, and better educated participants reported higher addictive use of SNS scores than others. Adjusted for these variables, masculine role discrepancy and discrepancy stress were positively associated, and self-esteem was negatively associated with addictive use of SNS scores. Path analysis indicated that masculine role discrepancy was associated with addictive use of SNS through discrepancy stress (mediation); self-esteem buffered (moderated) the association between masculine role discrepancy and discrepancy stress; self-esteem was not significantly associated with addictive use of SNS in this model with good fit. Discussion: The findings support the general strain theory's postulation that strain is associated with stress, which is in turn associated with addictive use of SNS sites. Implications, potential interventions, and future studies are discussed in this study.
\end{abstract}

Keywords: masculine role discrepancy, discrepancy stress, self-esteem, addictive use of social networking sites, male population

\section{INTRODUCTION}

\section{Addictive use of social networking sites (SNSs)}

Andreassen and Pallesen (2014, p. 4054) defined social networking addiction (SNA) as "being overly concerned about SNSs, to be driven by a strong motivation to log on to or use SNS, and to devote so much time and effort to SNS that it impairs other social activities, studies/job, interpersonal relationships, and/or psychological health and well-being." Similarly, Griffiths, Kuss, and Demetrovics (2014) defined that SNA occurs when the condition of SNS use fulfills six criteria (i.e., salience, mood modification, tolerance, withdrawal symptoms, conflict, and relapse). SNSs, such as Facebook, Twitter, Blog, and WeChat, are virtual communities where users can create individual public profiles, interact with real-life friends, and meet people based on shared interests (Brandtzæg \& Heim, 2009; Kuss \& Griffiths, 2011). These sites are predominantly visited, but not solely, for social purposes, such as making new friends, keeping in touch with existing friends, and general socializing with others (Brandtzæg \& Heim, 2009; Kuss \& Griffiths, 2011); other purposes include seeking/sharing information, debating, profile surfing, and entertainment (Ellison, 2007).

Recent evidence (e.g., Andreassen \& Pallesen, 2014; Xu $\&$ Tan, 2012) has suggested that some individuals may feel compelled to maintain their online social networks in a way that may lead to excessive and addictive use. For instance, $\mathrm{Xu}$ and Tan (2012) explained that when individuals view social networking as an important (or even exclusive) mechanism to relieve stressful feelings and other negative experiences, problematic social networking use would occur. A number of studies have investigated addictive use of

* Corresponding author: Joseph T. F. Lau, PhD; Faculty of Medicine, Centre for Health Behaviours Research, JC School of Public Health and Primary Care, The Chinese University of Hong Kong, Room 505, 5/F, Hong Kong SAR, China; Phone: +852 2637 6606; Fax: +852 2645 3098; E-mail: jlau@cuhk.edu.hk

This is an open-access article distributed under the terms of the Creative Commons Attribution-NonCommercial 4.0 International License, which permits unrestricted use, distribution, and reproduction in any medium for non-commercial purposes, provided the original author and source are credited, a link to the CC License is provided, and changes - if any - are indicated. 
SNS with assessment tools that are based on concepts of addiction, and found that it was positively associated with psychosocial and health-related problems, such as poor school performance, sleep problems, and relationship problems, and reduced engagements in real-life communities (e.g., Masters, 2015; Wang, Ho, Chan, \& Tse, 2015; Wu, Cheung, $\mathrm{Ku}, \&$ Hung, 2013). Thus, SNA is a commonly studied research topic that has practical implications. However, there are different views on whether or not severe SNS overuse should be regarded as an addictive behavior (Carbonell \& Panova, 2017). We used the term "addictive use of SNS" to consider the debate. It is considered as an emerging and potentially addictive behavior.

Globally, males often outnumber females in the prevalence of addictive behaviors, such as drug dependence, smoking, and alcoholism (Capraro, 2000; Li et al., 2011; Wilsnack, Vogeltanz, Wilsnack, \& Harris, 2000). Previous studies have shown that such addictive behaviors were associated with masculine role norms and related stress among males (Capraro, 2000; Courtenay, 2000; Reidy, Berke, Gentile, \& Zeichner, 2014, 2016). Regarding addictive use of SNS, which is emerging as a potentially addictive behavior, some studies found higher prevalence among males than females (Emre \& Isbulan, 2012; Vyjayanthi, Makharam, Afraz, \& Gajrekar, 2014), whereas others suggested an opposite relationship (Andreassen et al., 2016; Bányai et al., 2017). No study has investigated the relationships between masculine discrepancy/discrepancy stress and addictive use of SNS. We investigated how masculine role discrepancy, masculine role discrepancy stress, and selfesteem may be jointly associated with addictive use of SNS among males.

\section{Masculine role discrepancy and discrepancy stress}

Masculine role discrepancy arises when men perceive themselves not living up to the ideal manhood and being less masculine than the typical "man" (Reidy et al., 2014, 2016). These men may perceive or believe that other people would also perceive them as not being "masculine" (Reidy et al., 2016). People with perceived discrepancy may or may not feel stressful. When men perceive stressful feelings due to masculine role discrepancy, the condition is described as discrepancy stress (Reidy et al., 2016). Previous studies reported significant associations between masculine role discrepancy and discrepancy stress (Reidy et al., 2014, Reidy, Smith-Darden, Vivolo-Kantor, Malone, \& Kernsmith, 2017), but some authors speculated without testing empirically that perceived masculine role discrepancy does not always cause discrepancy stress (Reidy et al., 2016).

\section{Discrepancy stress and SNA}

Discrepancy stress can induce various problematic behaviors and maladaptive coping among males, such as injury, violence, and risky sexual behaviors (Reidy et al., 2014, 2016; Reidy, Smith-Darden, Cortina, Kernsmith, \& Kernsmith, 2015). Stress is a well-documented risk factor of males' addictive behaviors (e.g., drug abuse and Internet addiction; Jun \& Choi, 2015; Siegrist \& Rödel, 2006;
Sinha, 2001; Taylor et al., 1992). In this study, the general strain theory was used as the theoretical basis of our model. The theory asserts that various forms of strain (e.g., life stress and negative social relationships) can cause stressful feelings and negative emotions and subsequently lead to deviant behaviors or addiction as a coping strategy or escape from the negative feelings (Agnew \& White, 1992). The theory was originally developed to explain delinquency and crime (Agnew, 1992), and has been widely applied in various problematic behaviors, such as Internet addiction (Jun \& Choi, 2015), substance use (Özbay, 2014; Sharp, Peck, \& Hartsfield, 2012), problematic alcohol consumption (Swatt, Gibson, \& Piquero, 2007), disordered eating (Piquero, Fox, Piquero, Capowich, \& Mazerolle, 2010), aggression (Zapolski, Banks, Lau, \& Aalsma, 2018), cyberbullying (Jang, Song, \& Kim, 2014), and commercial sexual exploitation (Reid \& Piquero, 2016). Strain is a critical factor that causes individuals to conduct problematic behaviors (Agnew, 1992). A variety of strains have been found to result in such behaviors including academic stress, negative emotions, negative experiences in childhood, intimate partner violence, maternal depression, lack of social support, and parental criminality (Agnew, 1992; Jang et al., 2014; Jun \& Choi, 2015; Reid \& Piquero, 2016; Zapolski et al., 2018). In our case, masculine role discrepancy was found as a stressor; it would be associated with increased tension and negative feelings related to masculine role discrepancy; discrepancy stress in turn would increase the problematic behavior of addictive use of SNSs. Based on the theory and the relationship between masculine role discrepancy and discrepancy stress reported in previous studies, we hypothesized that masculine role discrepancy would be positively associated with discrepancy stress, which may in turn be positively associated with addictive use of SNS.

\section{Self-esteem and SNA}

Low self-esteem is also a well-documented risk factor of addictive use of SNS (e.g., Andreassen, Pallesen, \& Griffiths, 2017; Hong, Huang, Lin, \& Chiu, 2014). Some reports elaborated the context of the association. People with low self-esteem may regard SNS as a safer place to express themselves than people with high self-esteem (Forest \& Wood, 2012). They may see SNS as a preferred site for social interactions, as they can develop different profiles and enhance their self-esteem through such interactions (Andreassen, 2015). Furthermore, addictive use of SNS may reflect an attempt to inhibit one's negative self-concept (Andreassen et al., 2017). The beliefs that "I am not likable" or "I have poor social skills" together with the feeling that having many "friends/followers" through social networking would change such self-conceptions may encourage frequent use of SNS and induce addictive use of SNS.

\section{Self-esteem as a potential moderator of the relationship between masculine role discrepancy and discrepancy stress}

While some previous studies showed that masculine role discrepancy was associated with discrepancy stress 
(Reidy et al., 2014, 2017), it has also been pointed out that the relationship may not always exist (Reidy et al., 2016). Discrepancy stress may not occur to some men with masculine role discrepancy, if they possess positive self-concept and accept their gender role non-conformity. The argument implies that those with masculine role discrepancy, but high self-esteem may be less likely than others to develop discrepancy stress. Thus, it is possible that self-esteem would moderate the association between masculine role discrepancy and discrepancy stress. Such a hypothesis has not been tested in literature.

\section{The present study}

In a population-based study, we investigated the level of addictive use of SNS in the Hong Kong male adult general population and factors associated with addictive use of SNS, including sociodemographic factors and two gender-related variables (masculine role discrepancy and discrepancy stress) and self-esteem. We hypothesized that the genderrelated and self-esteem variables would be significantly associated with level of addictive use of SNS after being adjusted for significant sociodemographic variables. We then fit a model to look at the integrated potential impact of the two gender-related variables and self-esteem on addictive use of SNS. In this model, we first hypothesized that masculine role discrepancy would be positively associated with discrepancy stress, which would in turn be positively associated with addictive use of SNS; second, self-esteem would buffer (moderate) the association between masculine role discrepancy and discrepancy stress; third, self-esteem would be negatively associated with addictive use of SNS.

\section{METHODS}

\section{Study design and data collection}

This study is part of a large-scale survey that investigated sexual and behavioral health among males. Some results based on the data regarding depression and anxiety have been published (Yang, Lau, Wang, Ma, \& Lau, 2018). Ethical approval was obtained from the Survey and Behavioral Research Ethics Committee of the Chinese University of Hong Kong. Inclusion criteria of the study included: (a) Chinese males, (b) 18-60 years old, and (c) Hong Kong residents (holders of Hong Kong identification cards). Telephone numbers were randomly selected from the upto-date residential fixed-line phone directory. The interviews were conducted by well-trained and experienced interviewers of the authors' research center between 6:00 and 10:30 p.m. to avoid oversampling of unemployed individuals. Upon contact with a household member, the interviewers explained that the survey was anonymous and was related to male sexual and behavioral health. The eligible male member of each sampled household whose past birthday was closest to the day of the interview was invited to participate in the study. Participants were fully informed that their telephone number would not be recorded, and their responses would be maintained confidential. Verbal informed consent was sought before commencement of the survey. At least three attempts were made before unanswered telephone calls were considered as invalid numbers. A total of 3,091 eligible participants were contacted; 2,000 of them completed the interviews, giving a response rate of $65 \%$.

\section{Measures}

Masculine role discrepancy. Masculine role discrepancy was assessed using the 5-item Gender Role Discrepancy Subscale of the Masculine Discrepancy Stress Scale developed by Reidy et al. (2014, 2016). Participants rated the items on a 7-point Likert scale, ranging from 1 (strongly disagree) to 7 (strongly agree). Sample items include "I am less masculine than the average guy." The Chinese version was developed through a translation-back-translation procedure. The Cronbach's $\alpha$ was .82 in this study.

Discrepancy stress. Discrepancy stress was measured using the 5-item Discrepancy Stress Subscale of the Masculine Discrepancy Stress Scale (Reidy et al., 2014, 2016). Participants rated the items on a 7-point Likert scale, ranging from 1 (strongly disagree) to 7 (strongly agree). Sample items include "I worry that people judge me because I'm not like the typical man." The Chinese version was developed through a translation-back-translation procedure. The Cronbach's $\alpha$ was .65, which was not high but acceptable (Dukes, 2005).

Self-esteem. Self-esteem was assessed using the Rosenberg Self-Esteem Scale (Rosenberg, 1965). Ten statements are rated on a 4-point Likert scale ranging from 1 (strongly agree) to 4 (strongly disagree). The Chinese version has been validated (Cheng \& Hamid, 1995). Internal consistency of this scale was high in this study $(\alpha=.81)$.

Addictive use of SNS. Addictive use of SNS was assessed using the Chinese version of the Online Social Networking Addiction Scale (OSNA). In previous studies, the Facebook Addiction Scale (FAS; Koc \& Gulyagci, 2013) was adapted to form OSNA (Appendix; Li et al., 2016, 2017) by replacing the word "Facebook" by "social networking sites." The scale comprises eight items related to the symptoms of cognitive and behavioral salience, conflict with other activities, euphoria, loss of control, withdrawal, and relapse and reinstatement. OSNA thus assesses levels of addiction. The scale is anchored in the component models of Brown's (1993) and Griffiths' (2005) that postulate that addictions consist of a number of common components, such as salience, conflict, euphoria/mood modification, withdrawal, tolerance, and relapse; it is also in accordance with the diagnostic criteria of addiction (American Psychiatric Association, 1994). The OSNA significantly correlated with social networking activity intensity, Internet addiction, insomnia, and depression (Li et al., 2016, 2017). All questions refer to the experiences that occurred within the past month and are rated on a 5-point Likert scale spanning from 1 (not true) to 5 (extremely true). The total scores range from 8 to 40 ; higher scores indicate higher levels of addiction. There was no available cut-off point for categorical definition of 
addictive use of SNS; hence, the scale was used as a continuous variable. Internal consistency of the scale in this study was high $(\alpha=.82)$. Confirmatory factor analysis showed good model fit $\left[\chi^{2}(20)=226.17\right.$, $p<.05$, comparative fit index $(\mathrm{CFI})=0.95$, non-normed fit index $(\mathrm{NNFI})=0.94$, and the root mean square error of approximation $(\mathrm{RMSEA})=0.07]$.

\section{Data analyses}

Descriptive statistics were presented for background variables and psychological variables. Bivariate linear regression analysis was conducted for all the independent variables, including the background variables (regression coefficient: $B$ ). Multiple linear regression was conducted for the independent variables related to masculine role and selfesteem, adjusted for the significant background variables (Ba). SPSS version 21.0 was used.

Path analysis was conducted to test the proposed model and hypotheses with AMOS 19. The $\chi^{2}$ test, the CFI, the NNFI, and the RMSEA were used to test how well the model fits the observed data. Bootstrapping analyses were performed to identify the mediation effects of discrepancy stress. The $95 \%$ confidence interval (CI) of the indirect effect was obtained with 5,000 bootstrap resamples. Simple slope analyses were used to further interpret the moderation effect of self-esteem.

\section{Ethics}

The manuscript does not contain clinical studies or patient data. The study procedures were carried out in accordance with the Declaration of Helsinki. Ethical approval was obtained from the Survey and Behavioral Ethics Committee of the Chinese University of Hong Kong.

\section{RESULTS}

About half of the 2,000 participants $(47.60 \%)$ were aged $51-60$ years. The majority of them $(69.45 \%)$ were currently married or cohabitating with someone. There were $40.30 \%$ of the participants with college or above education levels (Table 1). In the sample, the mean scores [standard deviation $(S D)$ ] of masculine role discrepancy, discrepancy stress, self-esteem, and addictive use of SNS were 11.0 (5.40), 11.7 (4.85), 20.70 (4.50), and 10.39 (4.34), respectively.

As shown in Table 2, participants of younger age (reference group; $31-50$ years old: $B=-3.63, \beta=-0.39, p<.01$; 51-60 years old: $B=-4.51, \beta=-0.52, p<.01)$, being currently unmarried and not cohabiting with someone (reference group; married/cohabitating: $B=-2.66, \beta=-0.28$, $p<.01$; divorced/separated/widowed: $B=-3.18, \beta=-0.10$, $p<.01)$, and with higher education levels $(B=1.55$, $\beta=0.18, p<.01)$ were more likely to have higher addictive use of SNS scores than others. Masculine role discrepancy was significantly correlated with discrepancy stress $(r=.58$, $p<.01)$ and self-esteem $(r=-.39, p<.01)$, and discrepancy stress was negatively correlated with self-esteem $(r=-.24$, $p<.01)$. Adjusted for the significant sociodemographic variables (Table 3$)$, masculine role discrepancy $(\mathrm{Ba}=0.10$,
Table 1. Background characteristics of the participants

\begin{tabular}{lrc}
\hline & Frequency & Percentage (\%) \\
\hline Age (years) & & \\
$18-20$ & 104 & 5.20 \\
$21-30$ & 269 & 13.45 \\
$31-40$ & 228 & 11.40 \\
$41-50$ & 441 & 22.05 \\
$51-60$ & 952 & 47.60 \\
Missing & 6 & 0.30 \\
Current marital/cohabitation & status & \\
Currently unmarried and & 576 & 28.80 \\
$\quad$ non-cohabiting & 1,389 & 69.45 \\
Married/cohabitating & 35 & 1.75 \\
Divorced/separated/widowed & & \\
Education level & 1,194 & 59.70 \\
Secondary school or below & 806 & 40.30 \\
Tertiary education & & \\
\hline
\end{tabular}

Table 2. Associations between background variables and addictive use of SNS

\begin{tabular}{lcc}
\hline & $B[95 \% \mathrm{CI}]$ & $p$ value \\
\hline Age (years) & & \\
$18-30^{\mathrm{a}}$ & & \\
$31-50$ & $-3.63[-4.13,-3.12]$ & $<.01$ \\
$51-60$ & $-4.51[-4.99,-4.03]$ & $<.01$ \\
Marital/cohabitation status & \\
$\begin{array}{l}\text { Currently unmarried and } \\
\text { non-cohabiting }\end{array}$ & & \\
Married/cohabitating & $-2.66[-3.06,-2.25]$ & $<.01$ \\
Divorced/separated/ & $-3.18[-4.61,-1.76]$ & $<.01$ \\
$\quad$ widowed & & \\
Education level & & \\
Secondary school or & \\
below & & \\
Tertiary education & $1.55[1.17,1.94]$ & $<.01$ \\
\hline
\end{tabular}

Note. SNS: social networking site; CI: confidence interval. ${ }^{a}$ Reference group.

$\beta=0.12, \quad p<.01)$ and discrepancy stress $(\mathrm{Ba}=0.15$, $\beta=0.16, p<.01)$ were positively associated with addictive use of SNS scores; self-esteem $(\mathrm{Ba}=-0.05, \beta=-0.05$, $p=.03$ ) was negatively associated with addictive use of SNS scores, although it was not statistically significant in the bivariate regression analysis.

Our proposed model (Figure 1) fitted the data well $\left(\chi^{2}=3.14, \quad d f=2, \quad p=.21, \quad \mathrm{CFI}=0.99, \quad \mathrm{NNFI}=0.99\right.$, RMSEA = 0.02). In the model, masculine role discrepancy was positively associated with discrepancy stress $(B=0.53$, $p<.01)$; discrepancy stress was positively associated with addictive use of SNS $(B=0.13, p<.01)$. The indirect effect of masculine discrepancy stress on addictive use of SNS through discrepancy stress was statistically significant ( $B=0.07,95 \% \mathrm{CI}=0.06-0.09)$.

Regarding the role of self-esteem, it significantly moderated the association between masculine role discrepancy and discrepancy stress $(B=-0.11, p<.01)$. When selfesteem was low (1 $S D$ below the mean score), the association between masculine role discrepancy and discrepancy 
Table 3. Associations between psychological variables and addictive use of SNS

\begin{tabular}{lcccc}
\hline & $B[95 \% \mathrm{CI}]$ & $p$ value & Ba $[95 \% \mathrm{CI}]$ & $p$ value \\
\hline Model related to role discrepancy & & & & \\
Age & $\mathrm{N} / \mathrm{A}$ & $\mathrm{N} / \mathrm{A}$ & $-0.13[-1.57,-0.75]$ & $<.01$ \\
Marital/cohabitating status & $\mathrm{N} / \mathrm{A}$ & $\mathrm{N} / \mathrm{A}$ & $-0.18[-2.16,-1.25]$ & $<.01$ \\
Education level & $\mathrm{N} / \mathrm{A}$ & $\mathrm{N} / \mathrm{A}$ & $0.12[0.64,1.40]$ & $<.01$ \\
Role discrepancy & $0.13[0.09,0.16]$ & $<.01$ & $0.10[0.07,0.13]$ & \\
Model related to discrepancy stress & & & & \\
Age & $\mathrm{N} / \mathrm{A}$ & $\mathrm{N} / \mathrm{A}$ & $-0.12[-1.48,-0.67]$ & $<.01$ \\
Marital/cohabitating status & $\mathrm{N} / \mathrm{A}$ & $\mathrm{N} / \mathrm{A}$ & $-0.16[-2.01,-1.11]$ & $<.01$ \\
Education level & $\mathrm{N} / \mathrm{A}$ & $\mathrm{N} / \mathrm{A}$ & $0.11[0.62,1.37]$ & $<.01$ \\
Discrepancy stress & $0.21[0.17,0.25]$ & $<.01$ & $0.15[0.11,0.18]$ & $<.01$ \\
Model related to self-esteem & & & & $<.01$ \\
Age & $\mathrm{N} / \mathrm{A}$ & $\mathrm{N} / \mathrm{A}$ & $-0.14[-1.62,-0.79]$ & $<.01$ \\
Marital/cohabitating status & $\mathrm{N} / \mathrm{A}$ & $\mathrm{N} / \mathrm{A}$ & $-0.19[-2.27,-1.36]$ & $0.11[0.62,1.41]$ \\
Education level & $\mathrm{N} / \mathrm{A}$ & $\mathrm{N} / \mathrm{A}$ & $-0.05[-0.09,-0.01]$ & $<.01$ \\
Self-esteem & $-0.04[-0.08,0.01]$ & .11 & .03 \\
\hline
\end{tabular}

Note. B: bivariate regression coefficient; Ba: regression coefficients adjusted for the significant background variables; N/A: not applicable; SNS: social networking site; CI: confidence interval.

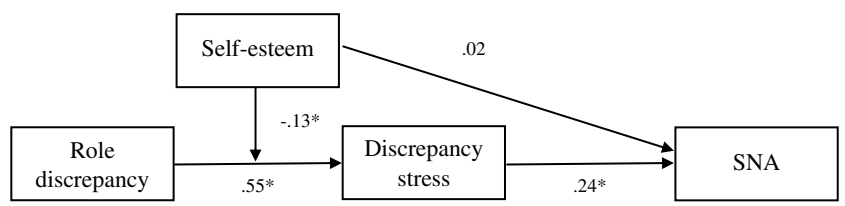

Figure 1. The proposed model with standardized path coefficients. Note. SNA: social networking addiction. ${ }^{*} p<.05$

stress was strong $(B=0.59, p<.01)$; when self-esteem was high (1 $S D$ above the mean), the strength of the association was smaller $(B=0.39, p<.01)$ (Figure 2$)$. In the model, self-esteem was neither significantly associated with discrepancy stress nor addictive use of SNS scores $(p>.05)$. The moderation effect had also a significant indirect effect on addictive use of SNS $(B=-0.01,95 \% \mathrm{CI}=-0.02$ to -0.01$)$.

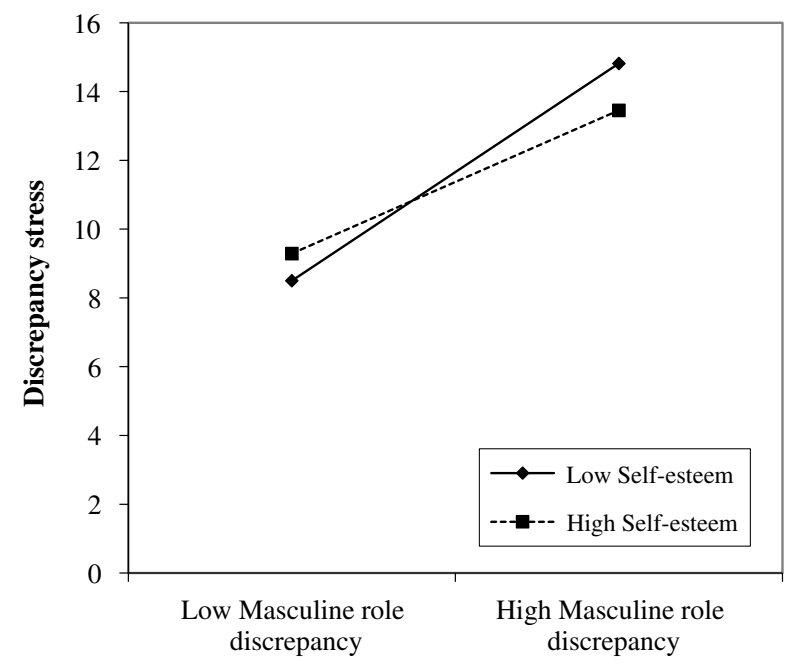

Figure 2. The simple slope analysis of the moderation effect

\section{DISCUSSION}

This study represents the first attempt to understand the potential roles of masculine role discrepancy, discrepancy stress, and self-esteem in influencing addictive use of SNS. This study was conducted in a relatively large random sample of Chinese adult males in Hong Kong.

Younger, currently unmarried, and non-cohabiting men were more likely to present higher levels of addictive use of SNS than other men. These results corroborate with previous studies (Andreassen, 2015; Andreassen et al., 2017; Griffiths, 2010). This has good face validity as the new younger generation (the so-called "digital natives" and "screenagers") often uses such technologies for leisure and social lives (Allen, Ryan, Gray, Mclnerney, \& Waters, 2014). Young people may also be more familiar with and willing to learn about, and be faster to adapt to new technological solutions and platforms (Andreassen \& Pallesen, 2014). Those who were not currently married tend to be younger and hence are also expected to show higher levels of addictive use of SNS. In addition, previous studies found that persons who are not in romantic relationships are more prone to developing addictive social media use than people who have regular partners (Kuss, Griffiths, Karila, \& Billieux, 2014), as SNS provides platforms for meeting new potential partners and experiencing feelings of belongingness (Andreassen, Torsheim, \& Pallesen, 2014). As a sizable proportion of the currently unmarried and non-cohabiting men may not be engaged in a romantic relationship, they are expected to have higher levels of addictive use of SNS. Furthermore, such men might have more time by themselves that allows them to visit SNSs, as they were not engaged in marriage. The findings may also support the social compensation ("poor get richer") hypothesis that people without a regular romantic relationship may be more likely to use SNS as a social compensation (Desjarlais \& Willoughby, 2010). We found that education levels were positively associated with addictive use of SNS scores. It supports the argument 
that people with higher education levels are more likely than others to use SNSs; such activities may increase their risk of addictive use of SNS (Andreassen et al., 2014; Correa, Hinsley, \& De Zuniga, 2010). Some authors, however, found that education level was negatively associated with level of addictive use of SNS (Andreassen et al., 2016, 2017). The findings were hence mixed. More studies on the relationship between education levels and addictive use of SNS are warranted.

Corroborating with previous studies (Andreassen et al., 2017; Hong et al., 2014), self-esteem was negatively associated with addictive use of SNS levels after controlling for the aforementioned significant background variables. It suggests that people might use social media to enhance positive self-feelings and/or to escape from negative feelings (Andreassen, 2015; Hong et al., 2014).

Previous studies on addictive use of SNS mainly focused on personality, personal needs, and self-esteem factors and less on social norms and stress-related factors (Andreassen \& Pallesen, 2014). A major contribution of the study is to introduce a model that explained how masculine role discrepancy, discrepancy stress, and self-esteem may be jointly associated with addictive use of SNS. In the model, the role of discrepancy stress in relating to males' addictive use of SNS was demonstrated by its mediation between masculine role discrepancy and addictive use of SNS. We have extended the application of the general strain model (Agnew \& White, 1992) to understand the relationship between masculine role discrepancy stress and addictive use of SNS, as the theory has been well supported by this study. It is plausible that the theory can further be applied to explore relationships between variables related to masculine role and other addictive behaviors, such as smoking, drug use, and alcohol use. Future studies would confirm these contentions and extend the applicability of the strain model. While we believe that OSNA is assessing addictive behaviors, the over use of SNSs may also be a type of coping with stress and daily hassles (Kardefelt-Winther, 2014). Thus, our findings also support the stress coping model that people might have used functions of the SNSs to reduce stressful feelings. Future longitudinal studies are needed to test such hypotheses.

The findings have further research implications. Men who deviate from social masculine role norms may encounter non-acceptance, stress, and stigma (Donaldson, 1993; Peralta, 2007). SNS may provide them with a comfortable social space that involves low risk of exposing their nonconformity and avoids experiencing anxiety/stigma that may occur during face-to-face interactions. It would be interesting to explore whether or not the model tested in this study can be applied to explain how addictive use of SNS (and other risk behaviors) would be affected by other deviations from social conformity/expectation that are socially undesirable, stigmatized, and stressful; examples of such conditions may include obesity, long-term unemployment, and minority sexual orientations.

We demonstrated self-esteem's buffering role in the association between masculine role discrepancy and discrepancy stress, that is, men with perceived masculine role discrepancy but positive overall views about themselves presented lower discrepancy stress than their counterparts who perceived masculine role discrepancy and had low selfesteem. The interaction between masculine role discrepancy and self-esteem was further associated with addictive use of SNS through decreased stress (mediation). The result is consistent with but not totally identical to the argument presented in previous studies that masculine role discrepancy does not always induce stress or negative reactions (Reidy et al., 2014, 2016). In our model, the association between masculine role discrepancy and discrepancy stress was weaker but still existed among those with lower selfesteem (1 $S D$ below the mean). Numerous studies have shown that self-esteem can potentially modify ones' stress appraisal and can buffer the negative effects of stressors on their reactivity (Cast \& Burke, 2002; Greenberg et al., 1992, 1993; Rector \& Roger, 1997). It is possible that men with higher self-esteem were less likely than others to appraise masculine role discrepancy as a stressor and thus perceived lower levels of stress, which may be associated with lower risk of addictive use of SNS. Future research may explore whether other potential buffers would play similar roles of self-esteem in moderating the association between masculine role discrepancy and discrepancy stress. For instance, personality (e.g., introversion and neuroticism) has been found to be associated with SNA and health-related problems (e.g., Barker, 2009). No study has looked at its moderation of the aforementioned association. Future studies may also look at other potential moderators, such as resilience, social support, and perceived impact of masculine role discrepancy.

Self-esteem was, however, not significantly associated with addictive use of SNS in the model. It was significant in the adjusted regression analysis, but that analysis did not consider the effects of discrepancy stress, which was controlled in the model. The finding suggests that discrepancy stress may be more predictive of addictive use of SNS than self-esteem. Previous studies have found that risk/negative factors, such as stress, often suggest potential costs and thus are weighted more heavily than positive factors (potential gain) in taking reactions or making decisions (Kanouse \& Hanson, 1971; Peeters \& Czapinski, 1990). Since this is the first study to include both self-esteem and discrepancy stress as the potential factors of addictive use of SNS, future works are required to validate this finding.

Given our findings, future studies may test the efficacy of the stress reduction and self-esteem enhancement interventions in preventing and mitigating addictive use of SNS, as discrepancy stress was found to be a risk factor and selfesteem a protective factor. Stress reduction programs may involve relaxation and stress management training to foster positive coping with discrepancy stress. Such interventions may buffer the negative impact of discrepancy stress on men's addictive use of SNS and other risk behaviors (Jakupcak, Lisak, \& Roemer, 2002; O’Neil, 1990). Cognitive-behavioral therapy (CBT) using cognitive restructuring and problem-solving techniques was effective for both stress reduction and self-esteem enhancement, and may also reduce addictive use of SNS directly (Andreassen \& Pallesen, 2014). Some gender-sensitive CBT (e.g., men's stress workshop) can also address masculinity-related stress and promote men's self-esteem explicitly (Primack, Addis, Syzdek, \& Miller, 2010). More research and tailored 
interventions are warranted to better understand and address the factors of addictive use of SNS.

This study has some limitations. The cross-sectional design cannot establish causal relationships; longitudinal studies are required for that purpose. The self-reported data may have been subjected to the common method bias (Podsakoff, MacKenzie, Lee, \& Podsakoff, 2003). Second, the Masculine Role Discrepancy Scale and Discrepancy Stress Scale have not been validated in the Chinese population; we tested internal consistency and the results were acceptable. The OSNA was adapted from the validated FAS and there is no clinical cut-off point. Future studies need to validate the OSNA. In addition, since the OSNA does not have a cut-off point, the prevalence of addictive use of SNS in the male population and those with high levels of masculine role discrepancy (stress) was unclear. In addition, no comparison with the female population was available. Third, our sample was older than the general male adult population in Hong Kong; $47.6 \%$ belonged to the age group of 51-60 years as compared to $30 \%$ of the census (Census and Statistics Department, 2017); this difference might have influenced the level of addictive use of SNS in our sample, since older age was associated with lower levels of addictive use of SNS. The prevalence of marital/cohabitation status and education level was similar to that reported in the census of Hong Kong (Census and Statistics Department, 2017). Fourth, other potential confounders that may affect addictive use of SNS (e.g., types and frequency of SNS use) need to be considered in future studies. Fifth, the study only tested masculine role discrepancy and related stress; the model may not be applicable to females. Future studies should develop related scales that are specific to feminine role discrepancy and test its factors and impact in female populations. Finally, sampling was based on landline residential telephone and did not include those who used mobile but not landline phones.

\section{CONCLUSIONS}

In conclusion, we found that males who were currently unmarried and non-cohabiting, younger, better educated, and having lower self-esteem showed higher levels of addictive use of SNS. In addition, masculine role discrepancy presented a stronger association with discrepancy stress among those with low self-esteem than those with high self-esteem. Discrepancy stress played a potentially important role in relating masculine role discrepancy to addictive use of SNS, as it mediated the relationship between masculine role discrepancy and addictive use of SNS. Self-esteem was protective of addictive use of SNS both through the aforementioned moderation effect on discrepancy stress in the path analysis and through a direct negative association with addictive use of SNS in the regression analysis. The findings provide new insights on the relationships between gender role-related variables and addictive use of SNS. With further research, the model developed by this study may be applicable to understanding similar relationships between masculine role-related variables and other risk behaviors, and potential impact of other types of strains on addictive use of SNS.
Funding sources: This work was supported by the Hong Kong Council for the AIDS Trust Fund (ref. no. MSS241R).

Authors' contribution: XY conceptualized the aims and hypotheses for the study and conducted analyses. XY and JTFL took primary responsibility for drafting the sections "Introduction," "Results," "Discussion," and tables. He designed the original study as principal investigator. ZW assisted with study design and data collection. MCML assisted with data collection. All authors have approved the final version of the manuscript.

\section{Conflict of interest: None.}

Acknowledgements: The authors would like to thank all of the participants who dedicated their time to completing this study and other fieldworkers who helped in the entire data collection period.

\section{REFERENCES}

Agnew, R. (1992). Foundation for a general strain theory of crime and delinquency. Criminology, 30(1), 47-88. doi:10.1111/j. 1745-9125.1992.tb01093.x

Agnew, R., \& White, H. R. (1992). An empirical test of general strain theory. Criminology, 30(4), 475-500. doi:10.1111/j. 1745-9125.1992.tb01113.x

Allen, K. A., Ryan, T., Gray, D. L., McInerney, D. M., \& Waters, L. (2014). Social media use and social connectedness in adolescents: The positives and the potential pitfalls. The Educational and Developmental Psychologist, 31(1), 18-31. doi:10.1017/edp.2014.2

American Psychiatric Association. (1994). Diagnostic and statistical manual of mental disorders (DSM-IV) (4th ed.). Washington, DC: American Psychiatric Association.

Andreassen, C. S. (2015). Online social network site addiction: A comprehensive review. Current Addiction Reports, 2(2), 175-184. doi:10.1007/s40429-015-0056-9

Andreassen, C. S., Billieux, J., Griffiths, M. D., Kuss, D. J., Demetrovics, Z., Mazzoni, E., \& Pallesen, S. (2016). The relationship between addictive use of social media and video games and symptoms of psychiatric disorders: A large-scale cross-sectional study. Psychology of Addictive Behaviors, 30(2), 252-262. doi:10.1037/adb0000160

Andreassen, C. S., \& Pallesen, S. (2014). Social network site addiction - An overview. Current Pharmaceutical Design, 20(25), 4053-4061. doi:10.2174/13816128113199990616

Andreassen, C. S., Pallesen, S., \& Griffiths, M. D. (2017). The relationship between addictive use of social media, narcissism, and self-esteem: Findings from a large national survey. Addictive Behaviors, 64, 287-293. doi:10.1016/j.addbeh.2016.03.006

Andreassen, C. S., Torsheim, T., \& Pallesen, S. (2014). Predictors of use of social network sites at work - A specific type of cyberloafing. Journal of Computer-Mediated Communication, 19(4), 906-921. doi:10.1111/jcc4.12085

Barker, V. (2009). Older adolescents' motivations for social network site use: The influence of gender, group identity, and 
collective self-esteem. CyberPsychology \& Behavior, 12(2), 209-213. doi:10.1089/cpb.2008.0228

Bányai, F., Zsila, Á., Király, O., Maraz, A., Elekes, Z., Griffiths, M. D., Andreassen, C. S., \& Demetrovics, Z. (2017). Problematic social media use: Results from a large-scale nationally representative adolescent sample. PLoS One, 12(1), e0169839. doi:10.1371/journal.pone.0169839

Brandtzæg, P. B., \& Heim, J. (2009). Why people use social networking sites. In A. A. Ozok \& P. Zaphiris (Eds.), International conference on online communities and social computing (pp. 143-152). Berlin/Heidelberg, Germany: Springer.

Brown, R. I. F. (1993). Some contributions of the study of gambling to the study of other addictions. In W. R. Eadington \& J. A. Cornelius (Eds.), Gambling behavior and problem gambling (pp. 241-272). Reno, NV: University of Nevada.

Capraro, R. L. (2000). Why college men drink: Alcohol, adventure and the paradox of masculinity. Journal of American College Health, 48(6), 307-315. doi:10.1080/07448480009596272

Carbonell, X., \& Panova, T. (2017). A critical consideration of social networking sites' addiction potential. Addiction Research \& Theory, 25(1), 48-57. doi:10.1080/16066359.2016.1197915

Cast, A. D., \& Burke, P. J. (2002). A theory of self-esteem. Social Forces, 80(3), 1041-1068. doi:10.1353/sof.2002.0003

Census and Statistics Department. (2017). Population and household statistics analysed by District Council district. Retrieved from https://www.censtatd.gov.hk/hkstat/sub/sp150.jsp

Cheng, S. T., \& Hamid, P. N. (1995). An error in the use of translated scales: The Rosenberg Self-Esteem Scale for Chinese 1. Perceptual and Motor Skills, 81(2), 431-434. doi: $10.1177 / 003151259508100214$

Correa, T., Hinsley, A. W., \& De Zuniga, H. G. (2010). Who interacts on the web?: The intersection of users' personality and social media use. Computers in Human Behavior, 26(2), 247-253. doi:10.1016/j.chb.2009.09.003

Courtenay, W. H. (2000). Behavioral factors associated with disease, injury, and death among men: Evidence and implications for prevention. The Journal of Men's studies, 9(1), 81-142. doi:10.3149/jms.0901.81

Desjarlais, M., \& Willoughby, T. (2010). A longitudinal study of the relation between adolescent boys and girls' computer use with friends and friendship quality: Support for the social compensation or the rich-get-richer hypothesis? Computers in Human Behavior, 26(5), 896-905. doi:10.1016/j.chb.2010. 02.004

Donaldson, M. (1993). What is hegemonic masculinity? Theory and Society, 22(5), 643-657. doi:10.1007/BF00993540

Dukes, K. A. (2005). Cronbach's alpha. In Armitage, P. (Ed.), Encyclopedia of biostatistics. Chichester, UK: Wiley.

Ellison, N. B. (2007). Social network sites: Definition, history, and scholarship. Journal of Computer-Mediated Communication, 13(1), 210-230. doi:10.1111/j.1083-6101.2007.00393.x

Emre, Ç. A. M., \& Isbulan, O. (2012). A new addiction for teacher candidates: Social networks. TOJET: The Turkish Online Journal of Educational Technology, 11(3), 14-19.

Forest, A. L., \& Wood, J. V. (2012). When social networking is not working: Individuals with low self-esteem recognize but do not reap the benefits of self-disclosure on Facebook. Psychological Science, 23(3), 295-302. doi:10.1177/0956797611429709

Greenberg, J., Pyszczynski, T., Solomon, S., Pinel, E., Simon, L., \& Jordan, K. (1993). Effects of self-esteem on vulnerabilitydenying defensive distortions: Further evidence of an anxiety-buffering function of self-esteem. Journal of Experimental Social Psychology, 29(3), 229-251. doi:10. 1006/jesp.1993.1010

Greenberg, J., Solomon, S., Pyszczynski, T., Rosenblatt, A., Burling, J., Lyon, D., Simon, L., \& Pinel, E. (1992). Why do people need self-esteem? Converging evidence that self-esteem serves an anxiety-buffering function. Journal of Personality and Social Psychology, 63(6), 913-922. doi:10.1037/00223514.63.6.913

Griffiths, M. (2005). A 'components' model of addiction within a biopsychosocial framework. Journal of Substance Use, 10(4), 191-197. doi:10.1080/14659890500114359

Griffiths, M. D. (2010). Trends in technological advance: Implications for sedentary behaviour and obesity in screenagers. Education and Health, 28(2), 35-38.

Griffiths, M. D., Kuss, D. J., \& Demetrovics, Z. (2014). Social networking addiction: An overview of preliminary findings. In K. P. Rosenberg \& L. C. Feder (Eds.), Behavioral addictions: Criteria, evidence, and treatment (pp. 119-141). London, UK: Academic Press.

Hong, F. Y., Huang, D. H., Lin, H. Y., \& Chiu, S. L. (2014). Analysis of the psychological traits, Facebook usage, and Facebook addiction model of Taiwanese university students. Telematics and Informatics, 31(4), 597-606. doi:10.1016/j. tele.2014.01.001

Jakupcak, M., Lisak, D., \& Roemer, L. (2002). The role of masculine ideology and masculine gender role stress in men's perpetration of relationship violence. Psychology of Men \& Masculinity, 3(2), 97-106. doi:10.1037/1524-9220.3.2.97

Jang, H., Song, J., \& Kim, R. (2014). Does the offline bully-victimization influence cyberbullying behavior among youths? Application of general strain theory. Computers in Human Behavior, 31, 85-93. doi:10.1016/j.chb.2013.10.007

Jun, S., \& Choi, E. (2015). Academic stress and Internet addiction from general strain theory framework. Computers in Human Behavior, 49, 282-287. doi:10.1016/j.chb.2015.03.001

Kanouse, D. E., \& Hanson, L. R. (1971). Negativity in evaluations. In E. E. Jones, D. E. Kanouse, H. H. Kelley, R. E. Nisbett, S. Valins, \& B. Weiner (Eds.), Attribution: Perceiving the causes of behavior. Morristown, NJ: General Learning Press.

Kardefelt-Winther, D. (2014). A conceptual and methodological critique of Internet addiction research: Towards a model of compensatory Internet use. Computers in Human Behavior, 31, 351-354. doi:10.1016/j.chb.2013.10.059

Koc, M., \& Gulyagci, S. (2013). Facebook addiction among Turkish college students: The role of psychological health, demographic, and usage characteristics. Cyberpsychology, Behavior, and Social Networking, 16(4), 279-284. doi:10. 1089/cyber.2012.0249

Kuss, D. J., \& Griffiths, M. D. (2011). Online social networking and addiction - A review of the psychological literature. International Journal of Environmental Research and Public Health, 8(9), 3528-3552. doi:10.3390/ijerph8093528

Kuss, D. J., Griffiths, M. D., Karila, L., \& Billieux, J. (2014). Internet addiction: A systematic review of epidemiological research for the last decade. Current Pharmaceutical Design, 20(25), 4026-4052. doi:10.2174/13816128113199990617

Li, J., Lau, J. T., Mo, P. K., Su, X., Wu, A. M., Tang, J., \& Qin, Z. (2016). Validation of the Social Networking Activity Intensity Scale among junior middle school students in China. PLoS One, 11(10), e0165695. doi:10.1371/journal.pone.0165695 
Li, J. B., Lau, J. T., Mo, P. K., Su, X. F., Tang, J., Qin, Z. G., \& Gross, D. L. (2017). Insomnia partially mediated the association between problematic Internet use and depression among secondary school students in China. Journal of Behavioral Addictions, 6(4), 554-563. doi:10.1556/2006.6.2017.085

Li, Y., Jiang, Y., Zhang, M., Yin, P., Wu, F., \& Zhao, W. (2011). Drinking behaviour among men and women in China: The 2007 China chronic disease and risk factor surveillance. Addiction, 106(11), 1946-1956. doi:10.1111/j.1360-0443. 2011.03514.x

Masters, K. (2015). Social networking addiction among health sciences students in Oman. Sultan Qaboos University Medical Journal, 15(3), e357-363. doi:10.18295/squmj.2015.15.03.009

O’Neil, J. M. (1990). Assessing men's gender role conflict. In D. Moore \& F. Leafgrean (Eds.), Problem solving strategies and interventions for men in conflict. Alexandria, VA: American Counseling Association.

Özbay, Ö. (2014). General strain theory and substance use Turkish Journal of Police Studies/Polis Bilimleri Dergisi, 16(1), 81.

Peeters, G., \& Czapinski, J. (1990). Positive-negative asymmetry in evaluations: The distinction between affective and informational negativity effects. European Review of Social Psychology, 1(1), 33-60. doi:10.1080/14792779108401856

Peralta, R. L. (2007). College alcohol use and the embodiment of hegemonic masculinity among European American men. Sex Roles, 56(11-12), 741-756. doi:10.1007/s11199-007-9233-1

Piquero, N. L., Fox, K., Piquero, A. R., Capowich, G., \& Mazerolle, P. (2010). Gender, general strain theory, negative emotions, and disordered eating. Journal of Youth and Adolescence, 39(4), 380-392. doi:10.1007/s10964-009-9466-0

Primack, J. M., Addis, M. E., Syzdek, M., \& Miller, I. W. (2010). The men's stress workshop: A gender-sensitive treatment for depressed men. Cognitive and Behavioral Practice, 17(1), 77-87. doi:10.1016/j.cbpra.2009.07.002

Podsakoff, P. M., MacKenzie, S. B., Lee, J. Y., \& Podsakoff, N. P. (2003). TCommon method biases in behavioral research: A critical review of the literature and recommended remedies. Journal of Applied Psychology, 88(5), 879-903. doi:10.1037/ 0021-9010.88.5.879

Rector, N. A., \& Roger, D. (1997). The stress buffering effects of self-esteem. Personality and Individual Differences, 23(5), 799-808. doi:10.1016/S0191-8869(97)00095-0

Reid, J. A., \& Piquero, A. R. (2016). Applying general strain theory to youth commercial sexual exploitation. Crime \& Delinquency, 62(3), 341-367. doi:10.1177/0011128713498213

Reidy, D. E., Berke, D. S., Gentile, B., \& Zeichner, A. (2014). Man enough? Masculine discrepancy stress and intimate partner violence. Personality and Individual Differences, 68, 160-164. doi:10.1016/j.paid.2014.04.021

Reidy, D. E., Berke, D. S., Gentile, B., \& Zeichner, A. (2016). Masculine discrepancy stress, substance use, assault and injury in a survey of US men. Injury Prevention, 22(5), 370-374. doi:10.1136/injuryprev-2015-041599

Reidy, D. E., Smith-Darden, J. P., Cortina, K. S., Kernsmith, R. M., \& Kernsmith, P. D. (2015). Masculine discrepancy stress, teen dating violence, and sexual violence perpetration among adolescent boys. Journal of Adolescent Health, 56(6), 619-624. doi:10.1016/j.jadohealth.2015.02.009

Reidy, D. E., Smith-Darden, J. P., Vivolo-Kantor, A. M., Malone, C. A., \& Kernsmith, P. D. (2017). Masculine discrepancy stress and psychosocial maladjustment: Implications for behavioral and mental health of adolescent boys. Psychology of Men \& Masculinity. Advance online publication. doi:10.1037/ men0000132

Rosenberg, M. (1965). Society and the adolescent self-image. Princeton, NJ: Princeton University Press.

Sharp, S. F., Peck, B. M., \& Hartsfield, J. (2012). Childhood adversity and substance use of women prisoners: A general strain theory approach. Journal of Criminal Justice, 40(3), 202-211. doi:10.1016/j.jcrimjus.2012.01.003

Sinha, R. (2001). How does stress increase risk of drug abuse and relapse? Psychopharmacology, 158(4), 343-359. doi:10.1007/ s002130100917

Siegrist, J., \& Rödel, A. (2006). Work stress and health risk behavior. Scandinavian Journal of Work, Environment \& Health, 32(6), 473-481. doi:10.5271/sjweh.1052

Swatt, M. L., Gibson, C. L., \& Piquero, N. L. (2007). Exploring the utility of general strain theory in explaining problematic alcohol consumption by police officers. Journal of Criminal Justice, 35(6), 596-611. doi:10.1016/j.jcrimjus. 2007.09.005

Taylor, S. E., Kemeny, M. E., Aspinwall, L. G., Schneider, S. G., Rodriguez, R., \& Herbert, M. (1992). Optimism, coping, psychological distress, and high-risk sexual behavior among men at risk for acquired immunodeficiency syndrome (AIDS). Journal of Personality and Social Psychology, 63(3), 460-473. doi:10.1037/0022-3514.63.3.460

Vyjayanthi, S., Makharam, S., Afraz, M., \& Gajrekar, S. (2014). Gender differences in the prevalence and features of Internet addiction among Indian college students. Medica Innovatica, 3(2), 65-70.

Wang, C. W., Ho, R. T., Chan, C. L., \& Tse, S. (2015). Exploring personality characteristics of Chinese adolescents with Internet-related addictive behaviors: Trait differences for gaming addiction and social networking addiction. Addictive Behaviors, 42, 32-35. doi:10.1016/j.addbeh.2014.10.039

Wilsnack, R. W., Vogeltanz, N. D., Wilsnack, S. C., \& Harris, T. R. (2000). Gender differences in alcohol consumption and adverse drinking consequences: Cross-cultural patterns. Addiction, 95(2), 251-265. doi:10.1046/j.1360-0443.2000. 95225112.x

Wu, A. M., Cheung, V. I., Ku, L., \& Hung, E. P. (2013). Psychological risk factors of addiction to social networking sites among Chinese smartphone users. Journal of Behavioral Addictions, 2(3), 160-166. doi:10.1556/JBA.2.2013.006

Xu, H., \& Tan, B. C. (2012). Why do I keep checking Facebook: Effects of message characteristics on the formation of social network services addiction. Proceedings of the International Conference on Informations Systems (ICIS), Orlando, FL. Retrieved from http://aisel.aisnet.org/cgi/viewcontent.cgi? article $=1216 \&$ context $=$ icis 2012

Yang, X., Lau, J. T., Wang, Z., Ma, Y. L., \& Lau, M. C. (2018). The mediation roles of discrepancy stress and self-esteem between masculine role discrepancy and mental health problems. Journal of Affective Disorders, 235, 513-520. doi:10.1016/j.jad.2018.04.085

Zapolski, T. C., Banks, D. E., Lau, K. S., \& Aalsma, M. C. (2018). Perceived police injustice, moral disengagement, and aggression among juvenile offenders: Utilizing the general strain theory model. Child Psychiatry \& Human Development, 49(2), 290-297. doi:10.1007/s10578-017-0750-z 


\section{APPENDIX}

Items of the Online Social Networking Addiction Scale (OSNA)

1. I have difficulties in focusing on my academic work due to my SNS use.

2. The first thing on my mind when I get up is log into SNS.

3. I lose sleep over spending more time on SNS.

4. My SNS use interferes with doing social activities.

5. I log into SNS to make myself feel better when I am down.

6. My family or friends think that I spend too much time on SNS.

7. I feel anxious if I cannot access to SNS.

8. I have attempted to spend less time on SNS but have not succeeded. 